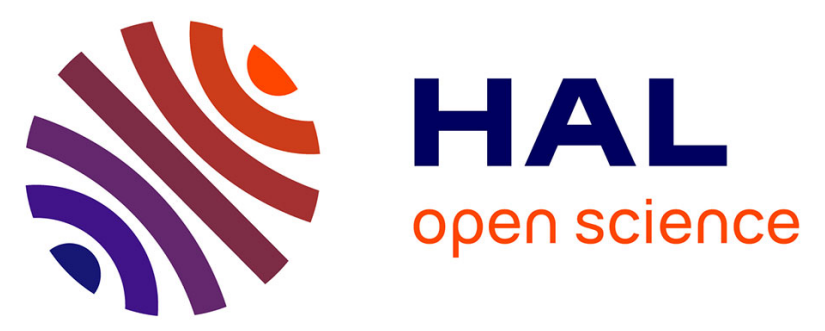

\title{
Atomic scale observation of phase separation and formation of silicon clusters in Hf higk- $\kappa$ silicates
}

\author{
Etienne Talbot, M. Roussel, C. Genevois, Philippe Pareige, Larysa
}

Khomenkova, X. Portier, Fabrice Gourbilleau

\section{- To cite this version:}

Etienne Talbot, M. Roussel, C. Genevois, Philippe Pareige, Larysa Khomenkova, et al.. Atomic scale observation of phase separation and formation of silicon clusters in Hf higk- $\kappa$ silicates. Journal of Applied Physics, 2012, 111, pp.103519. 10.1063/1.4718440 . hal-00738660

\section{HAL Id: hal-00738660 https://hal.science/hal-00738660}

Submitted on 21 Jun 2018

HAL is a multi-disciplinary open access archive for the deposit and dissemination of scientific research documents, whether they are published or not. The documents may come from teaching and research institutions in France or abroad, or from public or private research centers.
L'archive ouverte pluridisciplinaire HAL, est destinée au dépôt et à la diffusion de documents scientifiques de niveau recherche, publiés ou non, émanant des établissements d'enseignement et de recherche français ou étrangers, des laboratoires publics ou privés. 


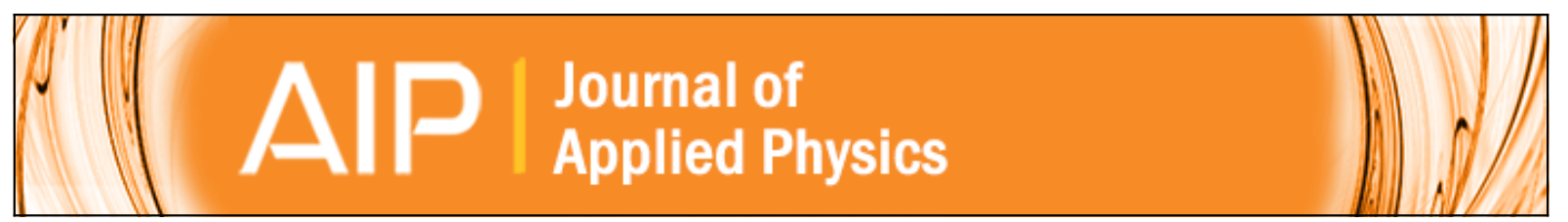

Atomic scale observation of phase separation and formation of silicon clusters in $\mathrm{Hf}$ higk- silicates

E. Talbot, M. Roussel, C. Genevois, P. Pareige, L. Khomenkova, X. Portier, and F. Gourbilleau

Citation: Journal of Applied Physics 111, 103519 (2012); doi: 10.1063/1.4718440

View online: http://dx.doi.org/10.1063/1.4718440

View Table of Contents: http://scitation.aip.org/content/aip/journal/jap/111/10?ver=pdfcov

Published by the AIP Publishing

\section{Articles you may be interested in}

Formation of silicon nanocrystals embedded in high- dielectric $\mathrm{HfO} 2$ and their application for charge storage J. Vac. Sci. Technol. B 29, 021018 (2011); 10.1116/1.3554736

The effect of nanocrystallite size in monoclinic $\mathrm{HfO} 2$ films on lattice expansion and near-edge optical absorption Appl. Phys. Lett. 96, 191904 (2010); 10.1063/1.3428965

Epitaxial growth of $\mathrm{Hf} \mathrm{O} 2$ doped $\mathrm{Ce} \mathrm{O} 2$ thin films on $\mathrm{Si}(001)$ substrates for high- application Appl. Phys. Lett. 92, 012915 (2008); 10.1063/1.2829792

Low-temperature method for enhancing sputter-deposited $\mathrm{Hf} \mathrm{O} 2$ films with complete oxidization Appl. Phys. Lett. 91, 012109 (2007); 10.1063/1.2753762

A thickness modulation effect of $\mathrm{Hf} \mathrm{O} 2$ interfacial layer between double-stacked Ag nanocrystals for nonvolatile memory device applications

J. Appl. Phys. 101, 026109 (2007); 10.1063/1.2430785

\section{AlP Re-register for Table of Content Alerts}




\title{
Atomic scale observation of phase separation and formation of silicon clusters in Hf higk- $\kappa$ silicates
}

\author{
E. Talbot, ${ }^{1, a)}$ M. Roussel, ${ }^{1}$ C. Genevois, ${ }^{1}$ P. Pareige,${ }^{1}$ L. Khomenkova, ${ }^{2}$ X. Portier, ${ }^{2}$ \\ and F. Gourbilleau ${ }^{2}$ \\ ${ }^{1}$ Groupe de Physique des Matériaux (GPM), Université et INSA de Rouen, UMR CNRS 6634, \\ Av. de l'Université, BP 12, 76801 Saint Etienne du Rouvray, France \\ ${ }^{2}$ Centre de Recherche sur les Ions, les Matériaux et la Photonique (CIMAP), CEA/CNRS/ENSICAEN/UCBN, \\ 6 Bd. Maréchal Juin, 14050 Caen Cedex 4, France
}

(Received 25 August 2011; accepted 17 April 2012; published online 21 May 2012)

\begin{abstract}
Hafnium silicate films were fabricated by $\mathrm{RF}$ reactive magnetron sputtering technique. Fine microstructural analyses of the films were performed by means of high-resolution transmission electron microscopy and atom probe tomography. A thermal treatment of as-grown homogeneous films leads to a phase separation process. The formation of $\mathrm{SiO}_{2}$ and $\mathrm{HfO}_{2}$ phases as well as pure $\mathrm{Si}$ one was revealed. This latter was found to be amorphous Si nanoclusters, distributed uniformly in the film volume. Their mean diameter and density were estimated to be about $2.8 \mathrm{~nm}$ and $(2.9 \pm 0.4) \times 10^{17} \mathrm{Si}-\mathrm{ncs} / \mathrm{cm}^{3}$, respectively. The mechanism of the decomposition process was proposed. The obtained results pave the way for future microelectronic and photonic applications of Hf-based high- $\kappa$ dielectrics with embedded Si nanoclusters. (C) 2012 American Institute of Physics. [http://dx.doi.org/10.1063/1.4718440]
\end{abstract}

\section{INTRODUCTION}

Continuous downscaling of the complementary metaloxide semiconductor technology has evidenced the limitations of the silicon oxide gate dielectrics for thickness lower than $0.7 \mathrm{~nm} .{ }^{1,2}$ To overcome this limit, alternative high- $\kappa$ materials have been proposed. Among them, zirconium and hafnium oxides, as well as their silicates are considered as the best candidates to replace $\mathrm{SiO}_{2}{ }^{3,4}$ Besides a high dielectric constant, the advantages of these materials are their thermal and chemical stabilities, and good interfacial quality with Si channel. ${ }^{3,5-7}$ Widespread applications of high- $\kappa$ materials are linked with the floating gate non-volatile memory devices containing semiconductor and/or metallic nanocrystals (NCs) or amorphous nanoclusters (ncs). ${ }^{8,9}$ Their controlled precipitation in high- $\kappa$ oxide host is a major challenge for such devices.

Among semiconductor NCs (or ncs), silicon and/or germanium ones are the most addressed. Their formation usually results from a two-step process. Initially, silicon (or germanium) is incorporated into high- $\kappa$ host. For this purpose, different techniques are used, for instance, $\mathrm{Si}(\mathrm{Ge})$ ion implantation ${ }^{10}$ or deposition of thin $\mathrm{Si}(\mathrm{Ge})$-based layer sandwiched between the high- $\kappa$ layers. ${ }^{11,12}$ After this step, a specific annealing treatment is carried out to form NCs (or ncs) inside high- $\kappa$ host. $^{10-12}$ It is worth to note that up to now neither Si-NCs nor Si-ncs formation in Hf-silicate host was demonstrated. To explain this fact, one can refer to a Hf-Si-O phase diagram. ${ }^{13-17}$ This pseudo-binary alloy can be accounted for a mixture of $\mathrm{HfO}_{2}$ and $\mathrm{SiO}_{2}$ unit cells such as $\left(\mathrm{HfO}_{2}\right)_{x}\left(\mathrm{SiO}_{2}\right)_{1-x} \cdot{ }^{13}$ They present a miscibility gap in the range of composition considered. This can lead to a phase separation process either during fabrication or post-fabrication processing. It results, usually, in

${ }^{a)}$ Electronic mail: etienne.talbot@univ-rouen.fr. the formation of $\mathrm{HfO}_{2}$ and $\mathrm{SiO}_{2}$ phases. ${ }^{16,17}$ Meanwhile, to our knowledge, no information was obtained about decomposition process for films as $\left(\mathrm{HfO}_{2}\right)_{x}\left(\mathrm{SiO}_{2}\right)_{y}$ with $x+y \neq 1$. As evoked previously, the formation of Si- or Ge-NCs (or ncs) requires an annealing treatment at $900-1100^{\circ} \mathrm{C} .^{10,18,25}$ If these $\mathrm{NCs}$ (or ncs) have to be grown in the Hf-silicate matrix, the thermal behaviour of this latter element has to be taking into account. $^{5,14,15,20}$

In this paper, we present a specific approach developed to fabricate Hf-silicate dielectrics with embedded Si-ncs. The films were grown by reactive RF magnetron sputtering, yielding on a fine control of their chemical composition. An annealing treatment was used to form Si-ncs. A combination of high-resolution transmission electron microscopy (HRTEM) and atom probe tomography (APT) techniques allowed to study the film microstructure at atomic scale level and to obtain information about a phase separation process and Si-ncs formation.

\section{EXPERIMENTAL}

\section{A. Fabrication of Hf-silicate samples}

For this study, a 230-nm HfSiO film was deposited on ptype (100) $\mathrm{Si}$ substrate cleaned in $10 \% \mathrm{HF}$ solution to remove native silicon oxide. The RF magnetron cosputtering of a 4-in. $\mathrm{HfO}_{2}$ target $(99.9 \%)$ topped by $\mathrm{Si}$ chips placed on the electron "race track" was used. The films were fabricated under a RF power density of $0.74 \mathrm{~W} / \mathrm{cm}^{2}$ and a substrate temperature of $400{ }^{\circ} \mathrm{C}$ in mixed argon-hydrogen plasma (with hydrogen flow rate of $20 \%$ ). The total plasma pressure was kept at $40 \mu$ bar. The hydrogen was used due to its ability to remove the oxygen from plasma and, in consequence, to reach higher $\mathrm{Si}$ excess in the films. More details on the reactive fabrication process can be found elsewhere. ${ }^{19,20}$ An annealing treatment of the sample was 
performed in a conventional furnace at $950^{\circ} \mathrm{C}$ during $15 \mathrm{~min}$ in a nitrogen flow.

\section{B. Methods used for structure analysis}

Several techniques were used to study the structural properties of the samples. X-ray diffraction analysis was performed using a Phillips XPERT HPD Pro device with $\mathrm{Cu} \mathrm{K}_{\alpha}$ radiation $(\lambda=0.1514 \mathrm{~nm})$ at a fixed grazing angle incidence of $0.5^{\circ}$. An asymmetric grazing geometry was chosen to increase the volume of material interacting with x-ray beam, as well as to eliminate the contribution from the Si substrate. attenuated total reflectance (ATR)-FTIR spectra were measured in the $600-4000 \mathrm{~cm}^{-1}$ spectral range by means of a $60^{\circ}$ Ge Smart Ark accessory inserted in a Nicolet Nexus spectrometer to study the chemical composition and microstructure of the samples. For atomic scale analysis of samples, APT and HRTEM were used. For this latter, the crosssectional specimens were prepared by a standard lift-out TEM lamella procedure. Z-contrast high angle annular dark field (HAADF), scanning transmission electron microscopy (STEM), electron energy loss spectroscopy (EELS), and HRTEM experiments have been performed by means of a JEOL-ARM200F working at $200 \mathrm{kV}$. APT techniques allow a chemical mapping of materials in three dimensions, in the real space with an atomic resolution. ${ }^{21-23}$ Laser assisted APT has been recently used to study insulating materials. ${ }^{24-26}$ It provides a better understanding of material nanostructure, allowing to quantify a phase separation process and to evidence clustering effects. To investigate Hf-silicate layer by this technique, tip shaped specimens were prepared by means of a dual-beam FIB-SEM (Zeiss NVision 40), using lift out method and an annular milling procedure. ${ }^{27,28}$ To prevent Ga implantation and ion beam amorphization, the samples were beforehand capped with a Pt layer. APT analyses were carried out in a laser assisted wide angle atom probe tomography (LAWATAP) from CAMECA. The experiments were carried out at $80 \mathrm{~K}$, using UV $(343 \mathrm{~nm})$ femtosecond laser pulses $(50 \mathrm{~nJ}, 350 \mathrm{fs})$ with a pulse rate of $100 \mathrm{kHz}$.

\section{RESULTS}

\section{A. As-grown HfSiO layers}

Structural properties of the sample, examined by x-ray diffraction and ATR-FTIR spectroscopy, showed the homogeneous and amorphous nature of the as-grown sample. ${ }^{5,20}$ These results were confirmed by HRTEM observations (Figure 1). The observed bright contrast at the film/substrate interface evidenced the formation of a thin interfacial $\mathrm{HfSiO}_{x}$ layer (not thicker than $1 \mathrm{~nm}$ ), as already shown for similar films by Khomenkova et al. ${ }^{5,20}$

\section{B. TEM observation of annealed HfSiO layers}

Figure 2 shows a cross-sectional HRTEM image of the $\mathrm{HfSiO}$ layers annealed at $950^{\circ} \mathrm{C}$ for $15 \mathrm{~min}$ in nitrogen flow. The bright and dark contrasts on HRTEM micrograph (see arrows) are associated with the formation of Si-rich and Hfrich phases due to the phase separation process in the $\mathrm{HfSiO}$ layer. The Hf-rich phase appears here to be crystallized,

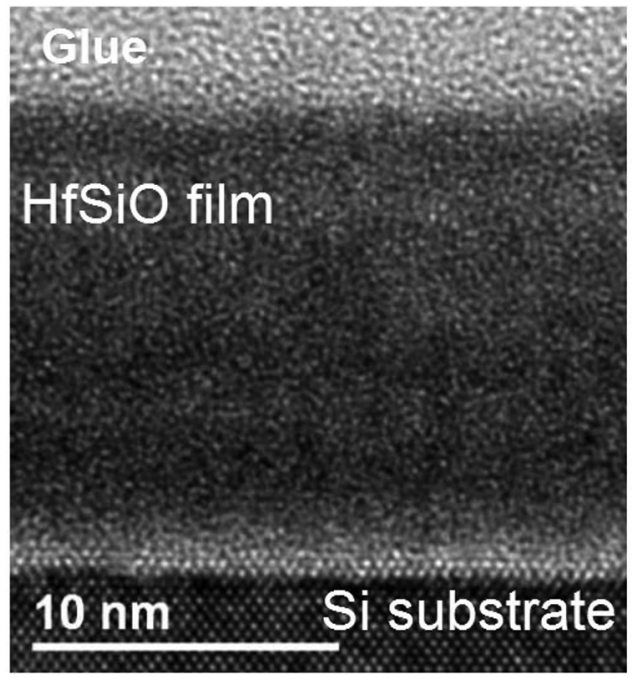

FIG. 1. Cross sectional HRTEM image of the as-grown HfSiO layer. Thin bright region close to substrate is $\mathrm{HfSiO}_{\mathrm{x}}$ interfacial layer.

which is consistent with previous study on the amorphouscrystalline transition on thick HfSiO layers. ${ }^{5}$ Thus, the detrimental role of thermal treatment resulting in the phase separation and formation of Hf-rich and Si-rich phases is clearly seen, as predicted by the phase diagram. Similar phase separation was already evidenced in the literature. ${ }^{5,16,29}$

Besides this phase separation in the film volume, the formation of two thin interfacial layers (IL) was observed. Based on their contrast, we can expect that the first IL (bright contrast, Si-IL, $\sim 2-\mathrm{nm}$ ) contains a lower amount of Hf than the second one (dark contrast, Hf-IL, 3-nm). To deeply investigate the nature of the phases formed as well as the origin of interface layer between $\mathrm{HfSiO}$ film and $\mathrm{Si}$ substrate, the analysis of the same sample by APT technique was performed.

\section{APT analysis of HfSiO layers}

A key point for high- $\kappa$ Hf-based microelectronic devices is the nature of film/substrate interface. The results of APT

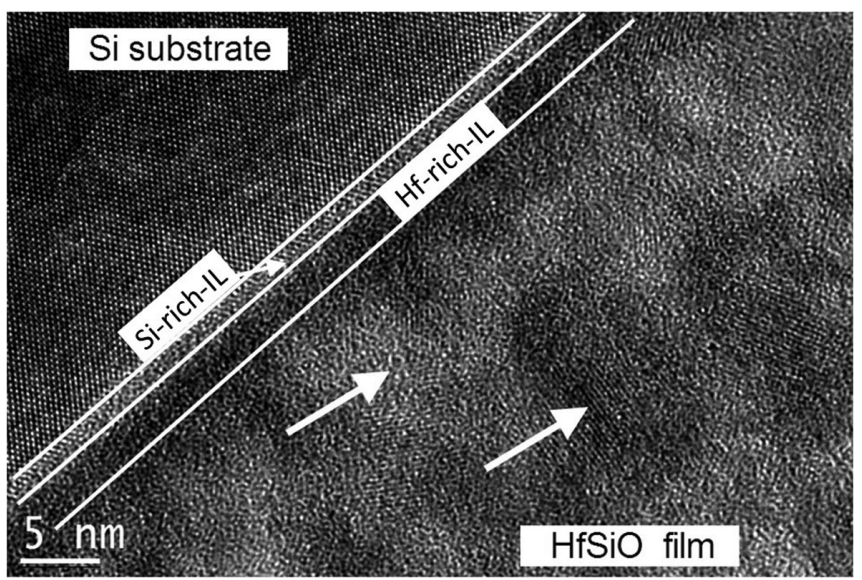

FIG. 2. Cross sectional HRTEM micrograph in [110] zone axis of the Si substrate. Si-IL denotes thin Si-rich layer at the interface with the silicon substrate, Hf-IL denotes Hf-rich interfacial layer followed Si-rich one. The arrows show the bright and dark regions, corresponding to Si-rich and Hf-rich phases formed in the film volume. The crystalline sequences are seen in the dark regions. 
experiments on the interface between $\mathrm{HfSiO}$ film and underlying Si substrate are shown in Fig. 3. A 3D reconstruction image of this interface region is displayed by Fig. 3(a). On this image, the hafnium and silicon atoms are presented by blue and red dots, respectively. The oxygen atoms are not shown here for clarity. The region $I$ corresponds to the $\mathrm{HfSiO}$ film that is separated by the interface layer (IL, region II) from the Si substrate (region III). At film/substrate interface (region II), the higher number of $\mathrm{Hf}$ atoms (blue dots) is found close to the $\mathrm{HfSiO}$ film (region I), whereas an enrichment in $\mathrm{Si}$ atoms (red dots) is clearly seen close to $\mathrm{Si}$ substrate (region III). Thus, this APT experiment confirms the formation of Si-rich IL layer followed by a Hf-rich one in the interface region. These results are consistent with the HRTEM observations described above.

Figure 3(b) represents the concentration profile for $\mathrm{Si}$, $\mathrm{O}$, and $\mathrm{Hf}$ (in at. \%) to the surface of the film towards the substrate. It has been calculated by counting the atoms of each species in a sampling volume of $25 \times 25 \times 1 \mathrm{~nm}^{3}$ parallel to the interface. The $\mathrm{Si}, \mathrm{O}$, and $\mathrm{Hf}$ content were found to be the same for different sampling volumes, chosen in the region $I$ (Fig. 3(b), depth before $15 \mathrm{~nm}$ ). The calculations showed that $X_{\mathrm{Si}}=30.6 \pm 0.3$ at. $\%, X_{\mathrm{O}}=61.5 \pm 0.3$ at. $\%$, and $X_{\mathrm{Hf}}=7.9 \pm 0.3$ at. $\%$ over all film volume.

The region $I I$ (depth between 16 and $21 \mathrm{~nm}$ ) shows also a mixture of Si-rich and Hf-rich phases. However, it is not
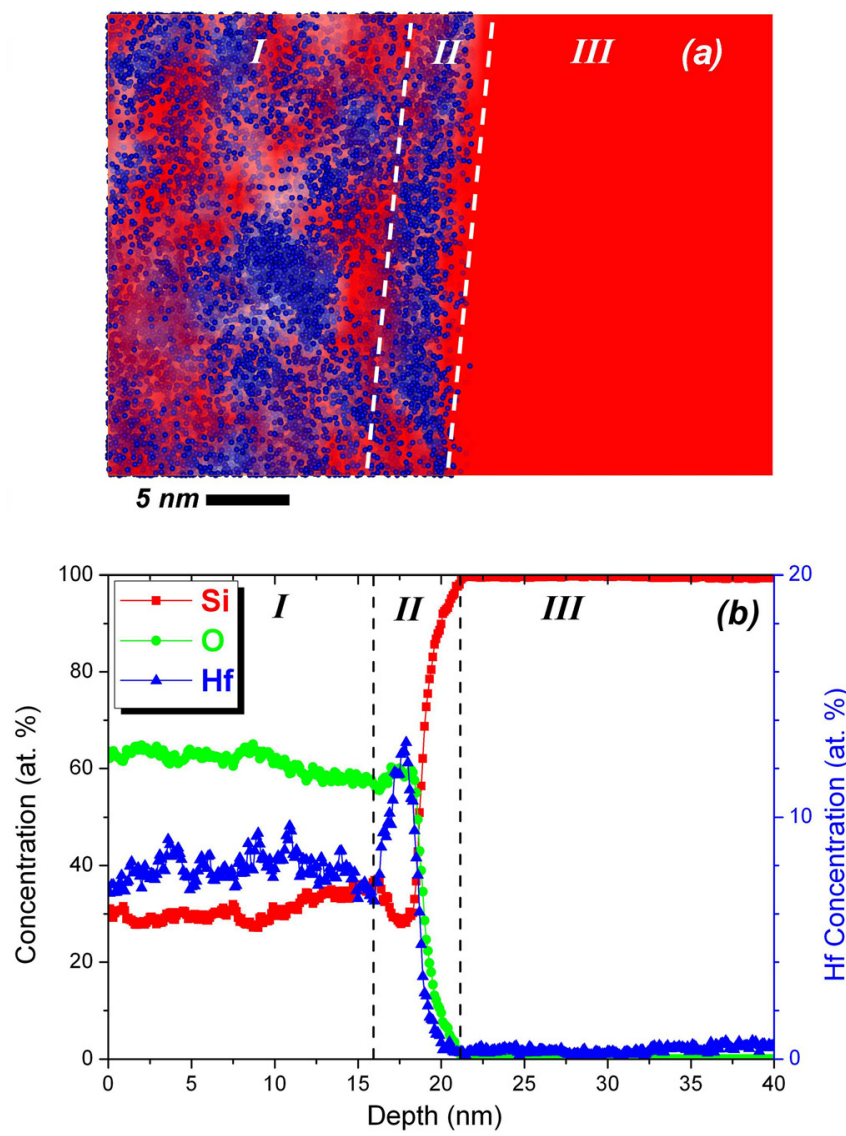

FIG. 3. APT reconstruction of the $\mathrm{HfSiO}-$ film/Si-substrate volume $\left(25 \times 25 \times 50 \mathrm{~nm}^{3}\right)$ analysed by LAWATAP. (a) Hafnium atom maps (blue dot) and silicon isoconcentration surface (red zones, $\mathrm{Si}>60$ at.\%). (b) $\mathrm{Si}, \mathrm{O}$, and $\mathrm{Hf}$ concentration profile (in at.\%) along the growth direction. homogeneous and contains two layers. The first one is enriched in hafnium (depth between 16 and $19 \mathrm{~nm}$ ) with the concentration of about 13 at. \% contrary to 7.9 at. \% observed for the film volume. The second layer (depth between 19 and $21 \mathrm{~nm}$ ) has higher Si content and its composition is close to $\mathrm{SiO}_{2}$. The thicknesses of Hf-rich and $\mathrm{SiO}_{2}$ layers were estimated to be $\sim 3 \mathrm{~nm}$ and $\sim 2 \mathrm{~nm}$, respectively, that is in a good agreement with HRTEM results (Fig. 2). The region III corresponds to the silicon substrate.

Figure 4 shows more detailed 3D chemical maps of a volume of the $\mathrm{HfSiO}$ film (region I), reconstructed after APT experiment, in which each dot represents one atom. For clarity, only $10 \%$ of $\mathrm{Si}$ and $\mathrm{O}$ atoms is shown in these maps. The analysis of the distribution of $\mathrm{Si}$ and $\mathrm{Hf}$ atoms demonstrates the presence of three different phases: (1) enriched in Hf (black arrow on Hf map), (2) depleted by Hf (white arrow on $\mathrm{Hf}$ map) as well as (3) enriched in $\mathrm{Si}$ (black arrow on $\mathrm{Si}$ map). Thus, it is clearly seen a phase separation process in the film volume, caused by high-temperature annealing. This is in agreement with HRTEM observation (Fig. 2).

In order to describe the spatial distributions of these phases, isoconcentration maps of silicon and hafnium atoms were calculated and are presented in Fig. 5. These filtered images show the three-phases system, where each phase is labelled as $\alpha$ (silica), $\beta$ (pure $\mathrm{Si}$ ), and $\gamma$ (hafnia). Local concentrations of $\mathrm{Si}, \mathrm{O}$, and $\mathrm{Hf}$ have been measured in each region and reported in Table I.

It is worth to note that atom probe measurements of the composition of nanometric clusters or small fluctuation area can be a difficult task due to artefacts generated by the difference in fields of evaporation between Si-ncs, Hafnia, and Silica. Indeed, this effect, already evidenced in similar

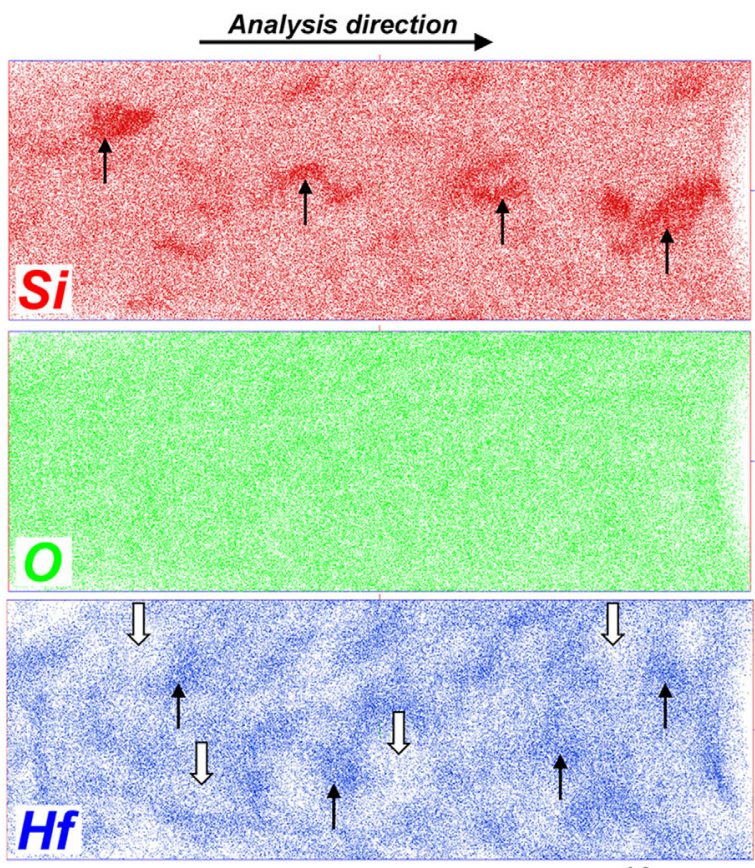

$\underline{10 \mathrm{~nm}}$

FIG. 4. 3D chemical maps of silicon (red), oxygen (green), and hafnium (blue) in a volume of $28 \times 28 \times 80 \mathrm{~nm}^{3}$. Hf-rich and Si-rich phases are indicated by black arrow and Hf-poor one with white arrow. 

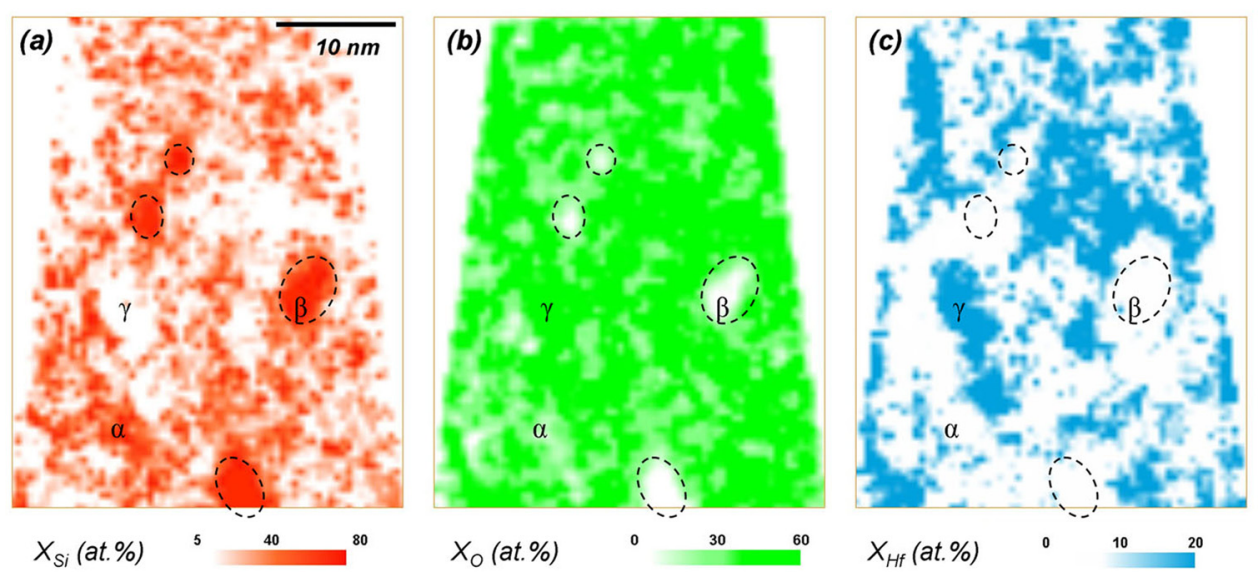

FIG. 5. Isoconcentration maps of silicon atoms (a); oxygen atoms (b), and hafnium atoms (c) in a selected volume $\left(5 \times 40 \times 50 \mathrm{~nm}^{3}\right)$. Different chemical zones, labelled as $\alpha$ (silica), $\beta$ (pure $\mathrm{Si}$ nc), and $\gamma$ (hafnia) are detected. Pure $\mathrm{Si}$ nanoclusters are highlighted with dashcircle.

materials, ${ }^{24,25}$ can introduce a bias for direct composition measurements. In our case, the concentration of Si-ncs, $\mathrm{SiO}_{2}$-rich, and $\mathrm{HfO}_{2}$-rich zones was corrected, applying the procedure developed by Talbot et al. ${ }^{24}$ Based on 3D chemical maps (Fig. 4) and isoconcentration maps (Fig. 5), we identified a thin $(<1-2 \mathrm{~nm})$ layer between the different phases $\left(\mathrm{SiO}_{2}, \mathrm{HfO}_{2}\right.$, and $\left.\mathrm{Si}-\mathrm{ncs}\right)$. It consists of $\mathrm{Hf}-\mathrm{Si}-\mathrm{O}$ demonstrating that the phase separation is not complete.

The diameter of individual Si-ncs was calculated by counting the number of $\mathrm{Si}$ atoms in each nanocluster. This latter was supposed to have a spherical shape. A dispersion in the size distribution (from $1 \mathrm{~nm}$ to $6.5 \mathrm{~nm}$ ) is observed with a mean gyration diameter of about $2.8 \mathrm{~nm}$. Taking into account the dimensions of the analysed volume, the Si-ncs density was estimated to be $(2.9 \pm 0.4) \times 10^{17} \mathrm{Si}-\mathrm{ncs} / \mathrm{cm}^{3}$.

\section{HAADF-STEM and EELS study of the annealed samples}

Phase separation in a mixture of Hf-rich and Si-rich phases in the Hf-Si-O layer was confirmed by a combined HAADF-STEM and EELS experiments. The corresponding HAADF images (sensitive to the Z-contrast) and EELS spectra (sensitive to local chemical composition) for HfSiO films are presented, respectively, on Fig. 6(a) and Figs. 6(b) and 6(c).

The HAADF-STEM image exhibits high-Z (bright) and low-Z (dark) contrast, identified as $\mathrm{HfO}_{2}$-rich $\left(\mathrm{Z}_{\mathrm{Hf}}=72\right.$ and $\mathrm{Z}_{\mathrm{O}}=8$ ) and $\mathrm{SiO}_{2}$-rich $\left(\mathrm{Z}_{\mathrm{Si}}=14\right)$ phases, respectively (Fig. 6(a)). This result has been confirmed by local EELS spectra performed on each contrasted zones. Both contrasted zones (Fig. 6(a)) contain oxygen (Fig. 6(b)), whereas bright and dark zones are hafnium and silicon rich regions, respectively (Fig. 6(c)). Moreover, O-K edge of $\mathrm{HfO}_{2}$-rich zones exhibits a low energy-loss shift compared to that of $\mathrm{SiO}_{2}$-rich ones,

TABLE I. Atomic concentration of $\mathrm{Si}, \mathrm{O}$, and $\mathrm{Hf}$ atoms in different regions labelled $\alpha, \beta$, and $\gamma$ on Fig. 5.

\begin{tabular}{lcrcc}
\hline \hline Label & $\mathrm{X}_{\mathrm{Si}}$ (at. \%) & $\mathrm{X}_{\mathrm{O}}($ at. \%) & $\mathrm{X}_{\mathrm{Hf}}$ (at. \%) & Phase \\
\hline$\alpha$ & $32.5 \pm 0.2$ & $66.2 \pm 0.2$ & $1.3 \pm 0.2$ & $\mathrm{SiO}_{2}$ \\
$B$ & $98.8 \pm 0.2$ & $1.2 \pm 0.2$ & 0.0 & $\mathrm{Si}$ \\
$\Gamma$ & 0.0 & $68.2 \pm 0.2$ & $31.8 \pm 0.2$ & $\mathrm{HfO}_{2}$ \\
\hline \hline
\end{tabular}

confirming the chemical difference between dark and bright zones. Such a result is in good agreement with a recent work of Agustin et al. ${ }^{30}$

\section{DISCUSSION}

Let's start the discussion by thermodynamic considerations of the Hf-silicate material. Dealing with thermodynamic equilibrium and Gibbs free energy of bulk $\mathrm{HfO}_{2}$ and $\mathrm{SiO}_{2}$ phases (respectively, $\mathrm{G}_{f}^{0}\left(\mathrm{HfO}_{2}\right)=-1238.7 \mathrm{~kJ} / \mathrm{mol}$ and $\left.\mathrm{G}_{f}^{0}\left(\mathrm{SiO}_{2}\right)=-981 \mathrm{~kJ} / \mathrm{mol}\right), \mathrm{HfO}_{2}$ phase is expected to be stable on silicon substrate without Hf silicide formation. However, several groups have reported about the formation of interfacial silicon oxide layer, when $\mathrm{HfO}_{2}$ film is in direct contact with Si substrate. The similar effect is shown in this paper. It was clearly demonstrated in Ref. 6 that the formation of this $\mathrm{SiO}_{2}-\mathrm{IL}$ is initiated by different diffusion processes. Among them, the most probable is oxygen out-diffusion from high- $\kappa$ regions close to the $\mathrm{Si}$ substrate towards the $\mathrm{Si}$ substrate surface. This can explain the appearance of coupled $\mathrm{SiO}_{2}$ rich and $\mathrm{HfO}_{2}$-rich layers following each other during an annealing.

Locquet et $\mathrm{al}^{31}$ have demonstrated the stability of such a layer introducing Gibbs free energy of an interfacial silicon oxide phase in the thermodynamic equations. Nevertheless, formation and stability of the $\mathrm{SiO}_{2}$-IL do not explain the origin of the observed continuous Hf-rich layer parallel to the substrate. This leads to an assumption of another decomposition mechanism. The thermodynamic analysis of thermal behaviour of bulk high- $\kappa$ silicates was performed by Kim and McIntyre. ${ }^{29}$ The silicates were considered as a supercooled liquid for typical transistor processing temperatures $\left(600-1000^{\circ} \mathrm{C}\right)$. The trend for the spinodal decomposition at lower temperatures is caused by negative Gibbs free energy of the silicates. Thus, a driving force for the decomposition process exists for initially homogeneous silicates and results in the formation of $\mathrm{SiO}_{2}$-rich phase (that contains more than 98 mol. \% of $\mathrm{SiO}_{2}$ ) and high- $\kappa$-rich (consists of more than $20 \mathrm{~mol}$. \% of high- $\kappa$ oxide phase) upon annealing. This phenomenon was found to be the main decomposition mechanism for the silicates with $40-90$ mol. $\%$ of $\mathrm{SiO}_{2}$ content. The consideration of the kinetics of this process revealed the presence of longitudinal composition waves in the bulk 
b)

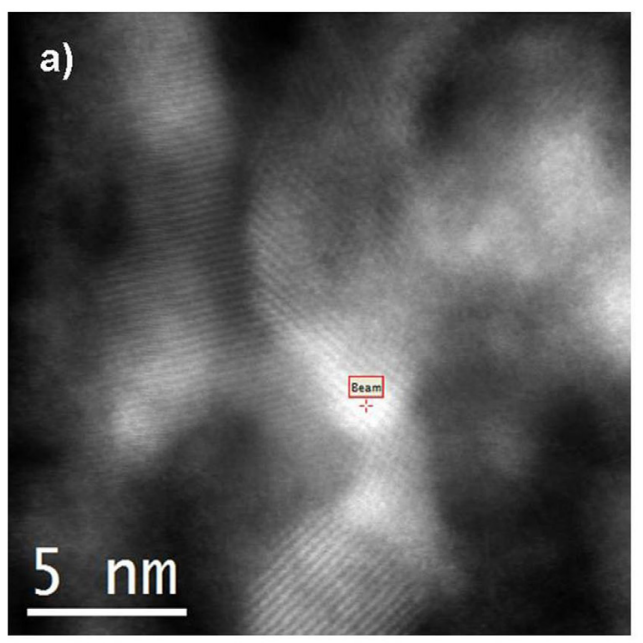

c)
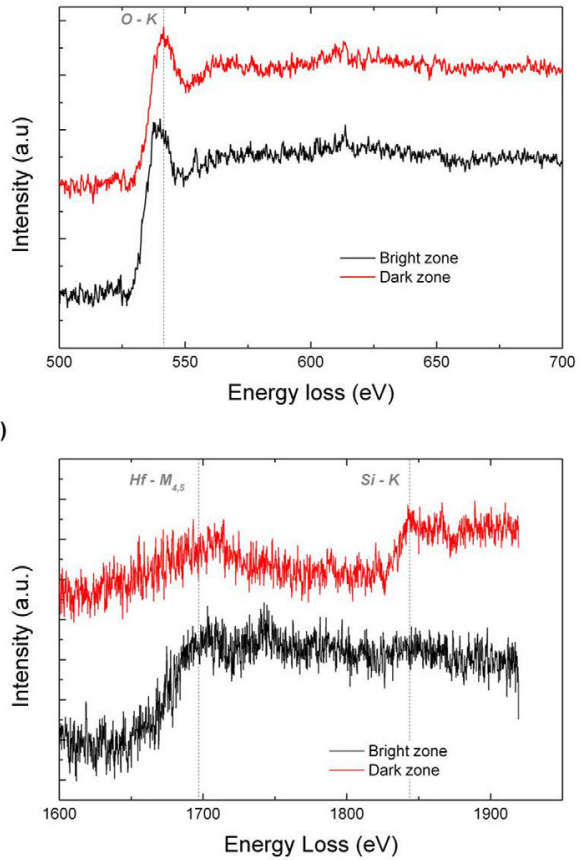

FIG. 6. Cross sectional HAADF-STEM image showing Hf-rich zones (bright contrast) and Hf-poor zones (dark contrast). EELS spectra obtained on bright and dark zones of the HAADF image for (b) O-K edge and (c) $\mathrm{Hf}_{-} \mathrm{M}_{4,5}$ and $\mathrm{Si}-\mathrm{K}$ edges. silicate. Meanwhile, for the film approach, this wave forms in the growth direction due to an effect of Si-subtrate/film interface. Consequently, formation of a layer structure, where $\mathrm{SiO}_{2}$-rich phase is alternated by high- $\kappa$-rich phase parallel to Si subtrate, occurs. It was shown that the silicate composition controls the number of these alternated layers (at other constant annealing parameters) and for the case of more than $50 \mathrm{~mol}$. \% of $\mathrm{SiO}_{2}$ content in high- $\kappa$ silicate films, only one $\mathrm{SiO}_{2}$ layer appeared at $\mathrm{Si}$ substrate surface followed by one high- $\kappa$-oxide-rich layer. As one can see from Fig. 2, these coupled layers are observed in our case. This is an evidence that interface-directed spinodal decomposition plays the main role in the structure evolution of samples investigated in this work. The similar formation of coupled $\mathrm{SiO}_{2}$-rich and $\mathrm{HfO}_{2}$-rich continuous layers due to spinodal decomposition mechanism of the film upon an annealing treatment was also observed in Refs. 5, 14, and 15. Meanwhile, any formation of Si-NCs (or ncs) was not evidenced in those works. In the present work, Si-ncs are imaged for the first time, despite that, this was not predicted by the model proposed by Kim and McIntyre. ${ }^{29}$

As one can see from Fig. 2, the annealing step at $950{ }^{\circ} \mathrm{C}$ during 15 min leads to the formation of a dual mixture of $\mathrm{SiO}_{2}$ and $\mathrm{HfO}_{2}$ phases as well as Si-ncs in the volume of silicate films, which is confirmed by the analysis of APT results. The formation of Si-ncs in the films investigated can be explained in the next way. Upon HfSiO film annealing, the formation of $\mathrm{HfO}_{2}$ phase is preferable due to ionic nature of $\mathrm{Hf}-\mathrm{O}$ bonds. As-grown films have a composition as $\mathrm{Hf}_{0.07} \mathrm{Si}_{0.33} \mathrm{O}_{0.60}$. Assuming that upon an annealing all Hf atoms are "catched" by $\mathrm{HfO}_{2}$ phase, then non-stoichiometric $\mathrm{SiO}_{x}$ phase (with $\mathrm{O} / \mathrm{Si}$ ratio of about 1.4) is formed instead of stoichiometric $\mathrm{SiO}_{2}$. Consequently, the formation of Si-ncs can occur due to decomposition of the $\mathrm{SiO}_{x}$ phase, similar to that observed for Si-rich$\mathrm{SiO}_{2}$ materials. ${ }^{9,19}$ It is worth to note that for $\mathrm{HfSiO}$ materials with about 20 at. $\%$ of $\mathrm{Hf}$ content, the formation of $\mathrm{HfO}_{2}$-rich and $\mathrm{SiO}_{2}$-rich phases occurred only upon post-deposition processing. ${ }^{5,15}$ No evidence of Si-ncs was reported in these works, ${ }^{5,15}$ confirming the effect of the Hf content in the film on the Si-ncs formation.

In the present work no crystalline plane sequences, which could correspond to Si-NCs, have been observed by HRTEM experiments. Moreover, either EFTEM or STEMEELS did not reveal their presence. This could be due to low density, small size as well as amorphous nature of these $\mathrm{Si}$ ncs. To go further in the conclusion and limits of EFTEM techniques to detect such clusters, additional experiments in the low energy-loss domain should be performed. On the contrary to TEM technique, APT showed that our sample contains about $(2.9 \pm 0.4) \times 10^{17} \mathrm{Si}-\mathrm{ncs} / \mathrm{cm}^{3}$. Thus, one can conclude that $\mathrm{Si}$ nanoclusters are mainly amorphous, which could be expected due to the annealing conditions.

\section{CONCLUSION}

In summary, new deposition approach has been proposed for the fabrication of HfSiO layers with specific composition. They have been characterized at the atomic scale by atom probe tomography and transmission electron microscopy. The information about decomposition of $\left(\mathrm{HfO}_{2}\right)_{x}\left(\mathrm{SiO}_{2}\right)_{y}$ $(\mathrm{x}+\mathrm{y} \neq 1)$ was obtained. A phase separation process in these materials occurs through the formation of $\mathrm{HfO}_{2}, \mathrm{SiO}_{2}$, and $\mathrm{Si}$ phases. The appearance of the last one depends strongly on the film composition and is possible for Hf-silicates with lower Hf content. The formation of Si-ncs in such films evidences the capability of magnetron sputtering technique for the production of future Si-rich-high- $\kappa$ materials, paving way for nanomemory applications. The results also demonstrate that APT and TEM are complementary techniques for atomic 
scale investigation of clustering and structural characterisation in higk $-\kappa$ materials.

\section{ACKNOWLEDGMENTS}

This work was supported by the Upper Normandy Region and the French Ministry of Research in the framework of Research Networks of Upper-Normandy. The growth of the layer is supported by the French National Research Agency (ANR) through Nanoscience and Nanotechnology Program (NOMAD Project No. ANR-07-NANO022-02), and for one of the authors (L. Khomenkova) by the Conseil Régional de Basse Normandie through the CPER project-Nanoscience axe (2007-2013).

${ }^{1}$ International Technology Roadmap for Semiconductors (ITRS), Semiconductor Industry Association, 2003. See http://public.itrs.net/.

${ }^{2}$ H. Wong and H. Iwai, Microelectron. Eng. 83, 1867 (2006).

${ }^{3}$ G. D. Wilk and R. M. Wallace, Appl. Phys. Lett. 74, 2854 (1999).

${ }^{4}$ G. D. Wilk, R. M. Wallace, and J. M. Anthony, J. Appl. Phys. 89, 5243 (2001).

${ }^{5}$ L. Khomenkova, C. Dufour, P. E. Coulon, C. Bonafos, and F. Gourbilleau, Nanotechnology 21, 095704 (2010).

${ }^{6}$ R. Jiang, E. Q. Xie, and Z. F. Wang, J. Mater. Sci. 42, 7343 (2007).

${ }^{7}$ M. A. Quevedo-Lopez, M. El-Bouanani, B. E. Gnade, R. M. Wallace, M. R. Visokay, M. Douglas, M. J. Bevan, and L. Colombo, J. Appl. Phys. 92, 3540 (2002).

${ }^{8}$ W. Li, R. Jia, C. Chen, M. Liu, H. F. Li, C. X. Zhu, and S. Long, ECS Trans. 18, 1071 (2009).

${ }^{9}$ L. Khomenkova, B. S. Sahu, A. Slaoui, and F. Gourbilleau, Nanoscale Res. Lett. 6, 172 (2011).

${ }^{10}$ B. Sahu, F. Gloux, A. Slaoui, M. Carrada, D. Muller, J. Groenen, C. Bonafos, and S. Lhostis, Nanoscale Res. Lett. 6, 177 (2011).

${ }^{11}$ H. Choi, M. Chang, M. Jo, S. Jung, and H. Hwang, Electrochem. SolidState Lett. 11, H154 (2008).
${ }^{12}$ W. L. Liu, P. F. Lee, J. Y. Dai, J. Wang, H. L. W. Chan, C. L. Choy, Z. T. Song, and S. L. Feng, Appl. Phys. Lett. 86, 013110 (2005).

${ }^{13}$ S. Monaghan, J. C. Greer, and S. D. Elliott, J. Appl. Phys. 97, 114911 (2005).

${ }^{14}$ J. Liu, X. Wu, W. N. Lennard, and D. Landheer, Phys. Rev. B 80, 041403 (2009).

${ }^{15}$ J. Liu, X. Wu, W. N. Lennard, D. Landheer, and M. W. C. Dharma-Wardana, J. Appl. Phys. 107, 123510 (2010).

${ }^{16}$ S. Stemmer, Y. Li, B. Foran, P. S. Lysaght, S. K. Streiffer, P. Fuoss, and S. Seifert, Appl. Phys. Lett. 83, 3141 (2003).

${ }^{17}$ D. A. Neumayer and E. Cartier, J. Appl. Phys. 90, 1801 (2001).

${ }^{18}$ M. Perego, G. Seguini, C. Wiemer, M. Fanciulli, P.-E. Coulon, and C. Bonafos, Nanotechnology 21, 055606 (2010).

${ }^{19}$ C. Ternon, F. Gourbilleau, X. Portier, P. Voivenel, and C. Dufour, Thin Solid Films 419, 5 (2002).

${ }^{20}$ L. Khomenkova, X. Portier, J. Cardin, and F. Gourbilleau, Nanotechnology 21, 285707 (2010).

${ }^{21}$ D. Blavette, A. Bostel, J. M. Sarrau, B. Deconihout, and A. Menand, Nature (London) 363, 432 (1993).

${ }^{22}$ D. Blavette, B. Deconihout, A. Bostel, J. M. Sarrau, M. Bouet, and A. Menand, Rev. Sci. Instrum. 64, 2911 (1993)

${ }^{23}$ G. Gault, F. Vurpillot, A. Vella, M. Gilbert, A. Menand, D. Blavette, and B. Deconihout, Rev. Sci. Instrum. 77, 043705 (2006).

${ }^{24}$ E. Talbot, R. Larde, F. Gourbilleau, C. Dufour, and P. Pareige, Europhys. Lett. 87, 26004 (2009).

${ }^{25}$ M. Roussel, E. Talbot, F. Gourbilleau, and P. Pareige, Nanoscale Res. Lett. 6, 164 (2011).

${ }^{26}$ R. Larde, E. Talbot, P. Pareige, H. Bieber, G. Schmerber, S. Colis, V. Pierron-Bohnes, and A. Dinia, J. Am. Chem. Soc. 133, 1451 (2011).

${ }^{27}$ D. J. Larson, D. T. Foord, A. K. Petford-Long, H. Liew, M. G. Blamire, A. Cerezo, and G. D. W. Smith, Ultramicroscopy 79, 287 (1999).

${ }^{28}$ G. B Thompson, M. K. Miller, and H. L. Fraser, Ultramicroscopy 100, 25 (2004).

${ }^{29}$ H. Kim and P. C. McIntyre, J. Appl. Phys. 92, 5094 (2002).

${ }^{30}$ M. P. Agustin, G. Bersuker, B. Foran, L. A. Boatner, and S. Stemmer, J. Appl. Phys. 100, 024103 (2006).

${ }^{31}$ J. P. Locquet, C. Marchiori, M. Sousa, J. Fompeyrine, and J. W. Seo, J. Appl. Phys. 100, 051610 (2006). 